\title{
What's in the pipeline? Drugs in development for autism spectrum disorder
}

\author{
This article was published in the following Dove Press journal: \\ Neuropsychiatric Disease and Treatment \\ 20 February 2014 \\ Number of times this article has been viewed
}

\author{
Min Sung' \\ Chee Hon Chin' \\ Choon Guan Lim' \\ Hwee Sen Alvin Liew' \\ Chau Sian Lim² \\ Espérance Kashala' \\ Shih-Jen Weng' \\ 'Department of Child and Adolescent \\ Psychiatry, Institute of Mental Health, \\ Singapore; ${ }^{2}$ Department of \\ Psychological Medicine, Khoo Teck \\ Puat Hospital, Singapore
}

Correspondence: Min Sung

Child Guidance Clinic, Health Promotion

Board Building, 3 Second Hospital

Avenue \#03-0I, 168937, Singapore

Tel +65 64353869

Fax +65 65343677

Emailmin_sung@imh.com.sg

\begin{abstract}
Autism Spectrum Disorder (ASD) is a complex neurodevelopmental disorder with both core symptoms and associated symptoms (eg, irritability, aggression, and comorbidities) that affect both the individual and the family/systems around them. There have been recent advances in the understanding of the underlying pathophysiology of ASD pertaining to genetics, epigenetics, neurological, hormonal, and environmental factors that contribute to the difficulties found in individuals with ASD. With this improved understanding, there has been a shift in the application of psychopharmacology in ASD and its related disorders. A literature review was conducted to examine research published in the last 5 years between different classes of psychotropic medications and ASD. The broad scope of the existing literature for the use of conventional medications is summarized and novel medications are discussed.
\end{abstract}

Keywords: pharmacology, treatment, autism, Asperger's syndrome, medication

\section{Introduction}

Autism Spectrum Disorder (ASD) is a complex disorder presenting with deficits in social interaction, social communication, and restricted, repetitive patterns of behaviors, interests, or activities. Currently, the Diagnostic and Statistical Manual of Mental Disorders, 5th Edition (DSM-5), and the International Statistical Classification of Diseases and Related Health Problems-10th Revision (ICD-10), are the dominant diagnostic classifications for this disorder. Pervasive Developmental Disorder - Not Otherwise Specified, as a category, remains less stable with higher degrees of variability in diagnosis within categorical and psychodynamic systems. ${ }^{1}$ The recently developed DSM-5 has reconceptualized the spectrum into a broad category - ASD and Social Communication Disorder. ${ }^{2}$ The diagnostic criteria for autism and its related disorders have been collapsed to encompass social communication and social interaction deficits as one criteria and restricted, repetitive patterns of behaviors, interests, and activities as the other. However, controversies remain with regards to categorization and diagnosis. This highlights the heterogeneity of the condition and the broader syndrome that we are considering when we examine literature on ASD.

ASD research continues to receive considerable attention as the options for successful management are limited. The understanding of the ASD etiology has now progressed to encompass genetic, epigenetics, neurological, hormonal, and environmental factors that affect outcomes for patients with ASD. ${ }^{3}$ With the increasing diversity of basic sciences and publications relating to pharmacological options for patients with ASD, a review of recent literature about the treatment advances in this field is warranted. The application of medication in patients with ASD has traditionally targeted associated 
conditions (such as inattention or irritability) that occur in the context of ASD, with poor evidence for the core symptoms of the condition. However, there are problems with the efficacy of medications in this population. In addition, children and young people with ASD also have a higher likelihood of developing intolerable side effects from the use of medications. Nevertheless, recent work has broadened the understanding of pharmacological use with newer medications being tried and studied in this population.

Electronic literature searches were conducted from the following sources: MedLine, the Cochrane Library, PsycARTICLES, and PsycINFO. Search terms included, but were not limited to, psychotropic medications (antidepressants, antipsychotics, mood stabilizers, melatonin, glutamate agonists, oxytocin, and attention deficit hyperactivity disorder (ADHD) medications (methylphenidate [MPH] and atomoxetine) autism, pervasive developmental disorders, ASD, and Asperger's syndrome from 2008 to 2013 (the last 5 years). The article abstracts obtained from the search strategy were perused and eligible articles were then retrieved. This article reviews recent evidence supporting various medications used in ASD. Evidence from trials published prior to 2008 was summarized to provide relevant background information.

\section{Scope of medications covered}

Conventional pharmacological management in ASD has targeted dysfunctional behavioral symptoms that interfere with rehabilitative efforts and cause impairment or distress, such as aggression, irritability, stereotyped behaviors, anxiety, hyperactivity, and sleep difficulties. ${ }^{4}$ These pharmacological agents include the antipsychotics, antidepressants, mood stabilizers, and medications targeting inattention and hyperactivity. Conventional treatments, with limited recent literature, have been summarized to provide an overview and will be covered briefly. The focus of this article will be on novel treatments with recent interest, including melatonin, omega-3 fatty acids, glutamate receptor related medications, and oxytocin. These will be described in greater detail.

\section{Antipsychotics}

Antipsychotics are the most-studied class of medications in the ASD population for efficacy and effectiveness.

Haloperidol has previously been well-studied for efficacy and safety. ${ }^{5}$ However, with concerns of extrapyramidal symptoms (EPS), ${ }^{6}$ typical antipsychotics have been dropped in favor of atypical antipsychotics, which have emerged as the first-line pharmacologic treatment for behavioral problems in $\mathrm{ASD} .^{7}$ As such, recent research in antipsychotic use in ASD has been limited to atypical antipsychotics.

While some atypical antipsychotics (such as risperidone and aripiprazole) have been better researched, others (such as olanzapine, quetiapine, and ziprasidone) have had limited data, with a few earlier case studies, open-label studies, or small double-blind placebo-controlled studies. ${ }^{8-15}$ No recent studies have focused on these drugs. Concerns with regards to adverse effects (such as metabolic side effects) may have resulted in limited use. . $^{5,16}$

Risperidone is a US Food and Drug Administration (FDA) approved antipsychotic for the treatment of symptoms in children and adolescents with ASD. ${ }^{7,17}$ Risperidone is useful in the management of behavioral problems, such as irritability, aggression, self-injurious behavior, hyperactivity, and repetitive behavior. ${ }^{18-21}$

Recent studies continue to demonstrate the efficacy of risperidone, ${ }^{22-24}$ and focus on its safety and side effects. The most common adverse effects are weight gain, increased appetite, and somnolence. ${ }^{22-25}$ Weight gain is a common problem and can cause significant health problems, ${ }^{22}$ while somnolence may more significantly affect treatment discontinuation. ${ }^{23}$ These side effects are more likely to occur in higher doses. ${ }^{24}$

There is interest in the combination of risperidone with other agents. For example, a small randomized controlled trial (RCT) showed that adding topiramate to risperidone was superior to risperidone alone in reducing irritability, stereotypic behavior, and hyperactivity. ${ }^{26}$ In similar RCTs, there was reported benefit in adding pentoxifylline, ${ }^{27}$ memantine, ${ }^{28}$ and celecoxib ${ }^{29}$ to risperidone in behavior problems. However, these results have not been verified in any other study.

Aripiprazole is the other FDA-approved atypical antipsychotic for use with children and adolescents with ASD. ${ }^{30,31}$ There have been two RCTs demonstrating the efficacy of aripiprazole in reducing irritability, hyperactivity, and stereotypies. ${ }^{32-34}$ The effect on irritability was sustained in an open-label follow-up trial of the above studies. ${ }^{35}$ Efficacy has also been demonstrated in another recent open-label ${ }^{36}$ study and a retrospective study. ${ }^{37}$ However, aripiprazole is not without side effects, which includes weight gain, sedation, sialorrhea, and EPS. ${ }^{30-34}$

There are only case reports documenting the use of clozapine in children and adolescents with ASD. Only one case report was published recently, on a 15-year-old girl with ASD, who previously failed treatment with risperidone and haloperidol. Her aggressive behavior dramatically improved 
with clozapine. ${ }^{38}$ However, the risk of agranulocytosis limits the use of clozapine.

Paliperidone, the active metabolite of risperidone, has been found to be generally well-tolerated and effective in the treatment in adolescents and young adults with ASD, but more research is still needed. It may have an advantage over risperidone in children with hepatic impairment, but paliperidone still shares a similar adverse effect profile as risperidone. ${ }^{17}$ Currently, published studies on the use of paliperidone in ASD are limited to an open-label trial ${ }^{39}$ and a few case reports. ${ }^{40,41}$ According to a recent open-label trial, side effects included weight gain, increased appetite, tiredness, EPS, and increased serum prolactin. In another case report, a 5-year-old boy with autism and severe aversion to oral medication was successfully treated with paliperidone palmitate given intramuscularly. ${ }^{41}$

There have been no recent published studies on the use of asenapine, sertindole, iloperidone, or amisulpride.

\section{Antidepressants}

Previous trials have suggested that children and adolescents with ASD showed improvements with fluoxetine. ${ }^{42,43}$ More recently, a double-blind placebo-controlled trial with fluoxetine in adult patients reported significant improvement in their obsessive-compulsive symptoms and overall symptoms. ${ }^{44}$ Although older trials did not find fluvoxamine to be effective in younger patients with $\mathrm{ASD}$, a randomized double-blind placebo-controlled crossover study reported that fluvoxamine was helpful in treating young patients, and found response to be related to polymorphism within a serotonin transporter gene. ${ }^{45}$ Improvements in anxiety, mood, and irritability have been suggested in studies on citalopram ${ }^{46}$ and escitalopram. ${ }^{47}$

In a recent meta-analysis of both published and unpublished randomized double-blind placebo-controlled trials examining the use of selective serotonin reuptake inhibitor (SSRI) in ASD, Carrasco et $\mathrm{al}^{48}$ reported a significant publication bias (ie, trials with positive results were more likely to be published). They found that although there was a significant treatment effect of SSRI (used for treating repetitive behaviors in ASD), these findings did not persist after they statistically adjusted for the publication bias. Meta-regression did not demonstrate a significant effect of SSRI treatment with age, although the trend among trials revealed that increased average patient age was associated with a greater treatment effect. ${ }^{48}$ A Cochrane review examined RCTs that studied the efficacy of several SSRIs (fluoxetine, fluvoxamine, fenfluramine, and citalopram) in treating ASD and reported that there was no evidence that SSRIs improved ASD symptoms, adding that it may even possibly cause harm. ${ }^{49}$

Clomipramine, with its SSRI properties and efficacy in treating obsessive compulsive disorder (OCD), is the most-studied tricyclic antidepressant. Previous double-blind trials suggested that clomipramine improved ASD symptoms, anger outbursts, repetitive behavior, hyperactivity, and irritability. ${ }^{50,51}$ In a Cochrane review on the efficacy of tricyclic antidepressants in treating ASD, three RCTs were examined. ${ }^{52}$ Clomipramine appeared to improve ASD symptoms, irritability, and OCD-type symptoms, but its effect on hyperactivity was not consistent.

Overall, the role of antidepressants remains unclear, and more research is needed. Children and adolescents with ASD appear to experience significant side effects, such as behavioral activation (hyperactivity and agitation), aggression, and suicidal ideation, ${ }^{53}$ all of which can limit its use.

\section{Mood stabilizers/antiepileptics}

A study found that divalproex was helpful for symptoms of irritability/aggression in children and adolescents with ASD, ${ }^{54}$ while findings in earlier studies were inconsistent. ${ }^{55,56}$

Findings on levetiracetam have been inconsistent, with an open-label study showing improved symptoms of aggression, impulsivity, hyperkinesis, and mood instability, ${ }^{57}$ while another, more recent placebo-controlled study reported no improvement in the behavioral problems associated with ASD. ${ }^{58}$

There have been no other recent positive findings for this class of medication and its use in ASD. However, it should be noted that this class of medication has significant side effects that limit its use in this population.

\section{Medications for ADHD}

MPH is a stimulant, which has been used in children with ASD and comorbid ADHD symptoms. However, its efficacy has been limited, due to the adverse side effects commonly reported in children with ASD, in comparison to children with ADHD alone. ${ }^{59,60}$ An earlier review suggested that MPH was superior to the placebo, but the response rate was low, and the side effects were prominent in children with ASD ${ }^{61}$ This suggests that MPH is not as efficacious in ASD as it is for ADHD.

Recently, there has been a slight shift to what was previously found, as few studies have started to report positive results with MPH in children with ASD. A study of 20 preschool children aged 3-5 years old with developmental disorders showed an improvement in the parents' rating of ADHD symptoms, although adverse events were more 
common. ${ }^{62}$ Another recent study also reported positive results with MPH on social communication and self-regulation in children with ASD and hyperactivity. ${ }^{63}$

Although MPH has been associated with more adverse events in children with ASD, a number of trials suggested beneficial results in children with ASD. ${ }^{65}$ Three RCTs have reported improvement of ADHD symptoms in children with ASD. ${ }^{66-67}$

Atomoxetine is a selective norepinephrine reuptake inhibitor, which is approved by the US FDA for the treatment of ADHD. It is a nonstimulant and, therefore, may offer better tolerability compared to $\mathrm{MPH} .{ }^{68} \mathrm{~A}$ recent review on atomoxetine suggested that its efficacy was most noticeable in individuals with a low severity of ASD. ${ }^{69}$ Additionally, in a 10 -week open-label study of 12 children with a high severity of ASD and symptoms of ADHD, results suggested that the participants did not benefit from atomoxetine and were more vulnerable to the adverse effects. ${ }^{70}$ On the contrary, a number of studies have suggested beneficial results on ADHD symptoms with atomoxetine in children with ASD. A recent open-label study showed improvement in ADHD symptoms and fewer adverse effects in individuals with ASD who also met criteria for ADHD. ${ }^{71}$ A recent double-blind placebocontrolled 8-week trial demonstrated the superior efficacy of atomoxetine compared to placebo on ADHD symptoms of children and adolescents with ASD. Additionally, improvements in ADHD symptoms were still observed after 28 weeks. $^{72}$ Several other studies have demonstrated improvements of ADHD symptoms with atomoxetine in children and adolescents with ASD. ${ }^{73-76}$ In a 10-week open-label study, positive results with atomoxetine were also reported in highfunctioning boys with ASD and comorbid ADHD. ${ }^{77}$

Guanfacine and clonidine (both alpha-2 adrenergic agonists) have been used in the treatment of ADHD. Contrary to clonidine, guanfacine has a longer half-life, which allows for lower dosing. In addition, it has fewer sedative effects. In earlier trials, guanfacine has been found to be effective in the ASD population in reducing hyperactivity, inattention, and impulsivity. ${ }^{78-80} \mathrm{Clo-}$ nidine is an FDA-approved medication, used as an adjunction medication in the traditional treatment of ADHD. ${ }^{81}$ In previously published double-blind trials, clonidine was reported to reduce irritability, hyperactivity, and impulsivity. ${ }^{82,83}$ However, the lack of current research in this area limits the conclusions that can be drawn for the use of clonidine in treating ASD.

\section{Novel treatments}

The quest to develop drugs to effectively target socialization and communication in ASD has been challenging. Factors contributing to this difficulty include the lack of specific understanding of the neurobiology of ASD, the heterogeneity of the condition, and the natural course of gradual improvement in these core symptoms over time. However, a number of drugs are beginning to show promise in the area and deserve further study ${ }^{84}$ Recent studies have also focused on medications traditionally regarded as complementary agents, suggesting potential benefits. These medications offer novel options to the practicing clinician in the management of the ASD population and, hence, have been presented in more detail.

\section{Melatonin}

An endogenous neurohormone, melatonin is secreted by the pineal gland, causing drowsiness. Melatonin levels increase rapidly after nightfall, peak in the middle of the night, and decrease toward dawn. Melatonin has been increasingly used to manage sleep disorders in children with ASD. In the last 5 years, various retrospective studies, open-label trials, and placebo-controlled trials have been conducted.

In a retrospective study on 107 children (aged 2-18 years old) with ASD, $85 \%$ of parents reported partial or full improvement in sleep. ${ }^{85}$ Another case series studied six adults with ASD on melatonin retrospectively and reported improvements in long sleep latency, night waking, and settling difficulties. ${ }^{86} \mathrm{~A}$ recent open-label trial ${ }^{87}$ studied melatonin in 24 children with ASD over a 14-week intervention. Supplemental melatonin improved sleep latency in most children at 1 or $3 \mathrm{mg}$ doses, within 1 week of treatment.

Small RCTs with melatonin have also shown promise. In a randomized, double-blind crossover trial in 18 children with $\operatorname{ASD}(n=8)$ and/or Fragile $X$ syndrome, there was a significant increase in total sleep time and decrease in sleep latency in melatonin compared to placebo. ${ }^{88}$ Another randomized, double-blind crossover trial was conducted on 22 children and adolescents with ASD involving 3 months of placebo and 3 months of melatonin. Melatonin significantly improved sleep latency and total sleep, and the side effect profile was low. ${ }^{89}$ In addition, a randomized placebo-controlled trial examining insomnia in children with ASD was conducted. In their study, they compared melatonin alone, melatonin combined with cognitive behavioral therapy, cognitive-behavioral therapy and placebo in children with ASD. ${ }^{90}$ Findings suggested that adding behavioral intervention to melatonin treatment, resulted in better treatment response, at least in the short term.

Melatonin appears to have potential in the treatment of sleep problems in ASD, although larger trials are needed. 


\section{Omega-3 fatty acids}

A group of polyunsaturated fatty acids, the three main types found in the human diet are ALA (alpha-linolenic acid), DHA (docosahexaenoic acid), and EPA (eicosapentaenoic acid). DHA and EPA are found in seafood, while ALA is found in nut and plant oils. While the human body can synthesize both DHA and EPA from ALA, it cannot synthesize any of these fatty acids from scratch. Thus, these substances are called "essential fatty acids." Neural tissue contains high concentrations of DHA, and studies suggest that this fatty acid is essential to the growth and functional development of the brain. ${ }^{91}$ Several studies have also reported low levels of omega-3 fatty acids in children with ASD compared to controls. ${ }^{92}$ The RCTs of omega-3 supplementation have been conducted for the treatment of ADHD, depression, and schizophrenia. ${ }^{93}$

A recent Cochrane review was done on omega-3 fatty acids supplementation for ASD in 2011. ${ }^{93}$ In the review, the authors highlighted two studies in which children who were diagnosed with ASD were randomized into groups that received either omega-3 fatty acid supplementation or a placebo. Overall, there was no evidence that the omega-3 supplementation had an effect on social interaction, communication, stereotypy, or hyperactivity. The largest positive effect for treatment was reported for hyperactivity. However, since the sample size was small, the findings may not have been sufficient to provide robust evidence. Larger clinical trials are currently ongoing, and the results would lend better clarity.

\section{Glutamate receptor-related medications}

Glutamate, the main excitatory neurotransmitter in our central nervous system, has been implicated in ASD. Glutamate is converted to gamma-amino butyric acid (GABA) in the brain by the glutamic acid decarboxylase protein. Related epigenetic factors involving GABA receptor genes have been associated with ASD. ${ }^{94}$ Studies that have been initially performed suggest that GABA-signaling pathways are associated with stereotypies in a large proportion of experimental animal models for ASD, including Fragile X syndrome. ${ }^{95-97}$ Similarly, there are reports suggesting associations between ASD and gene variations for glutamate receptors and glutamate transporter proteins. ${ }^{98,99}$

In one study in humans, the GABA type A receptors were found to be reduced in three brain sites which were possibly linked with the development of ASD, leading to the suggestion of extensive GABAergic dysfunctions in the brains of individuals with ASD. ${ }^{100}$ The plasma levels of glutamate and glutamine were found to be high in children with highfunctioning $\mathrm{ASD},{ }^{101}$ leading to the postulation that the plasma levels of glutamate and glutamine could serve as early markers of glutamatergic dysfunction in ASD. In addition, an increased GABA level in the plasma of individuals with ASD has also been found. ${ }^{102}$ In another study, an abnormality in the proportion of GABA to the glutamate level in the brains of individuals with ASD has also been suggested. ${ }^{103}$ A recent review paper by Essa et al suggested that excessive glutamatergic activity might cause excitotoxicity in the brain that might result in the abnormal development of neurons leading to ASD. ${ }^{104}$

Various medications that work within the glutamatergic system, including at the N-methyl-D-aspartate (NMDA) subtype of the glutamate receptor, have been studied for their roles in treating ASD and the related symptoms. Glutamate antagonists work by blocking the glutamate receptor and moderating excessive excitation at the neuronal level. In one animal model, a glutamate antagonist, 2-methyl-6(phenylethynyl)pyridine (MPEP) was studied in relation to autism. Although the authors have suggested that metabotropic glutamate receptor 5 (mGluR5) antagonism might be effective in the treatment of stereotypic behaviors, the MPEP might have adverse effects on the core symptoms of ASD (sociability). It was further postulated that the MPEP's effects appeared to be complex and inconsistent, which could have resulted in improvements in some aspects of sociability but worsening in others. ${ }^{105,106} \mathrm{In}$ a recently published animal model study using D-cycloserine, an NMDA-receptor agonist, the authors suggested that there were improvements in social behavior when used concurrently with social behavioral therapy. In addition, it was postulated that glutamate transmission might have a role in the development of social bonds in animals and that D-cycloserine enhances the assimilation of social information. ${ }^{107}$

Studies have also moved toward investigating glutamate receptor-related medications in clinical populations. In a double-blind clinical trial by Lemonnier et al, the diuretic, chloride-importer antagonist bumetanide, which reduces intracellular chloride and enhances GABAergic inhibition, was studied. ${ }^{108}$ In this study, bumetanide showed significant improvements in the Childhood Autism Rating Scale, and Clinical Global Impressions and Autism Diagnostic Observation Schedule after eliminating the most severe cases. Side effects of mild hypokalemia were noted. As such, the authors went on to suggest that bumetanide could be a promising novel agent in treating ASD and highlighted the need for further extensive trials. 
One of the more commonly known NMDA-receptor antagonists is memantine, which has been used in the treatment of Alzheimer's dementia. Memantine serves as a moderate affinity antagonist of the NMDA receptor. In a retrospective open-label study of 18 patients (6-19 years of age) with ASD, who were treated with memantine, eleven out of 18 responded with improvements in social withdrawal and inattention. ${ }^{109}$ However, in the same study, seven out of 18 patients developed adverse effects, which included sedation, irritability, rash, emesis, and increased seizure frequency.

In another open-label study by Niederhofer, which studied the effects of memantine (20 mg per day for 4 weeks) in four children with ASD, the findings revealed significant improvements in irritability, hyperactivity, and inappropriate speech. ${ }^{110}$ Similarly, an earlier study involving individuals with ASD showed improvements in the areas of hyperactivity, irritability, lethargy, and memory tests. ${ }^{111}$

Recently, there has been interest in the effects of combining memantine with risperidone. For example, in a 10-week, randomized double-blind, placebo-controlled trial, memantine combined with risperidone was prescribed to 40 children (4-12 years of age). The results demonstrated significant improvements in the memantine group in terms of irritability, stereotypic behavior, and hyperactivity. Such a combination was also well-tolerated. The authors concluded that memantine might be a potential adjunctive treatment strategy for individuals with ASD. ${ }^{29}$ In an earlier open-label add-on therapy study involving memantine, which spanned across a 21-month period with individuals with autism and ASD, participants showed significant improvements in their language functioning, social, and - to a lesser degree - selfstimulatory behaviors. ${ }^{112}$

Acamprosate, a GABA type A agonist and excitatory glutamate antagonist, has also been studied in a recent open-label study. Erickson et al posited that it brought about significant improvements in social withdrawal, hyperactivity, Social Responsiveness Scale, and Clinical Global Impression-Severity scale scores. ${ }^{113}$

The literature, both in the animal and human studies, has suggested that glutamate abnormalities are present in animal models with stereotypies and in clinical populations with ASD. Questions remain unanswered for the specific etiologies resulting in abnormal glutamate levels, which can range from dietary origin to glutamate receptor/transporter problems. However, with this improved understanding of the possible etiology underlying this disorder, pharmacological strategies targeting the glutamate receptors now show promise in ASD, particularly for the core symptoms of stereotypical and social behaviors.

\section{Oxytocin}

Recent research has suggested that the neuropeptide oxytocin may play a role in the etiology of ASD. Oxytocin is synthesized in the magnocellular neurons in the paraventricular nucleus and the supraoptic nucleus of the hypothalamus. It is released into the bloodstream by way of the axon terminals in the posterior pituitary. It is released both peripherally (where it is involved in milk letdown and the facilitation of uterine contractions) and centrally, where it acts as a neuromodulator along with arginine vasopressin. Oxytocin (and arginine vasopressin) may play a neuromodulatory role in affiliative and sexual behaviors, separation distress, social memory and recognition, stress response, and the regulation of feeding and grooming. It has been suggested that oxytocin abnormalities may exist in ASD. ${ }^{114}$

Early studies investigated the effects of oxytocin infusion. Findings suggested that oxytocin infusions reduced repetitive behaviors and improved affective speech comprehension from pre- to postinfusion. ${ }^{115,116}$ Recent studies have focused on investigating social behaviors in ASD with intranasal oxytocin. In a study that investigated the behavioral effects of oxytocin in 13 subjects with ASD, findings suggested that after an oxytocin infusion, subjects exhibited stronger interactions and increased eye gaze. ${ }^{117}$ In another singlearmed, open-label study in which oxytocin was administered intranasally to eight male youths with ASD, six of the eight participants showed improved scores on the communication and social interaction domains of the Autism Diagnostic Observation Schedule-Generic (ADOS-G). No side effects were noted. ${ }^{118}$

Several small randomized trials have also been done. In a double-blind, randomized, placebo-controlled crossover trial, an oxytocin nasal spray or placebo was administered to 16 male youths with ASD. ${ }^{119}$ In comparison with the placebo, the oxytocin administration improved performance on the Reading the Mind in the Eyes Task. ${ }^{119}$ Another pilot, randomized, double-blind, placebo-controlled, parallel design trial was conducted whereby intranasal oxytocin was compared to placebo in 19 adults with ASD. ${ }^{120}$ Results also suggested improvements after 6 weeks in measures of social cognition. Additionally, oxytocin was reported to be well-tolerated. ${ }^{120}$ Finally, in another trial, intranasal oxytocin was administered to 14 individuals with ASD and 14 neurotypical control participants. They then performed a face-matching and a house-matching task during functional 
magnetic resonance imaging. The study was tested in a randomized, placebo-controlled, within subject, crossover design. After oxytocin, right amygdala activity to facial stimuli increased in the ASD group, relative to the control group. ${ }^{121}$

Oxytocin shows promise as a drug targeting the core social and communication deficits in ASD. Further studies with larger sample sizes would be needed to ascertain the efficacy of oxytocin.

\section{Conclusion}

The current clinical practice in psychiatry focuses on the use of medications in ASD by targeting specific associated symptoms, not unlike that in the management of other mental health conditions. There are well-established and licensed antipsychotic medications for the treatment of specific symptoms associated with ASD. For example, risperidone and aripiprazole target the management of symptoms, such as irritability and hyperactivity. Findings from trials for other medications have been less consistent. For example, antidepressants and mood stabilizers have been reported to be associated with tolerability issues that need to be balanced against possible benefits. The use of atomoxetine and stimulants remains positive for targeted symptoms, although the ASD population is potentially more vulnerable to adverse events. These medications, coupled with a good clinical understanding of the patient's strengths and difficulties, as well as functional analysis of behavior combined with psychological strategies, may be helpful for some persons with ASD. While the associated symptoms in ASD may be ameliorated, many of these symptoms are manifestations that stem from the core social communication difficulties and repetitive, restricted behaviors in this population. For instance, anxiety in ASD may result from difficulties in peer interactions or problems adjusting to changes in the environment. This intrinsically limits the benefits from traditional pharmacology as the core deficits in ASD are not directly addressed.

Recent research in ASD has moved toward investigating the etiological factors contributing to this complex spectrum of disorders. There is now a growing body of research on genetics, epigenetics, neurological abnormalities, neurotransmitters, hormonal, immunological, prenatal, and environmental factors in ASD. For instance, some studies have investigated the association between immunological factors, such as human leukocyte antigen alleles and ASD. ${ }^{122,123}$ Calcium channel membrane proteins, such as the synaptosomal-associated protein of $25 \mathrm{KD}$ (SNAP 25) and the soluble N-ethylmaleimide-sensitive factor attachment protein receptor (SNARE) protein have also been implicated and findings suggest that polymorphisms of the SNAP25 gene may be linked to symptomatology in ASD. ${ }^{124,125}$ This move toward understanding the basis of ASD will allow a better conceptualization of the disorder from a biological perspective and allow more accurate definition and diagnosis. From a clinical perspective, this will also serve a pivotal role in the clinical approach to managing ASD. Pharmacologically, this will allow the development of medications targeting the biological basis of ASD, hence being more specific and potentially improving the core deficits of this condition. Much of the research in this direction is currently laboratory based. However, there is potential for this work to extend to clinical applicability. Work in glutamate and oxytocin has moved from genetic, epigenetic, and neuronal studies to animal models and, currently, to clinical trials. While findings are preliminary, there are indications that there could be potential benefits in the social communication and repetitive behavioral difficulties with these medications. This calls for collaborative bench to bedside research between scientists and clinicians with a view to breaking new ground in the development of new drugs in the management of ASD.

\section{Disclosure}

The authors report no conflicts of interest in this work.

\section{References}

1. Chiappedi M, Rossi G, Rossi M, Bejor M, Balottin U. Autism and classification systems: a study of 84 children. Ital J Pediatr. 2010;36:10.

2. American Psychiatric Association. Diagnostic and Statistical Manual of Mental Disorders. 5th ed. Arlington, VA: American Psychiatric Publishing; 2013.

3. Kumar B, Prakash A, Sewal RK, Medhil B, Modi M. Drug therapy in autism: a present and future perspective. Pharmacol Rep. 2012;64(6): 1291-1304.

4. Sung M, Fung DSS, Cai YM, Ooi YP. Pharmacological management in children and adolescents with pervasive developmental disorders. Aust N Z J Psychiatry. 2010;44(5):410-428.

5. Malone RP, Waheed A. The role of antipsychotics in the management of behavioural symptoms in children and adolescents with autism. Drugs. 2009;69(5):535-548

6. Campbell M, Armenteros JL, Malone RP, Adams PB, Eisenberg ZW, Overall JE. Neuroleptic-related dyskinesias in autistic children a prospective, longitudinal study. J Am Acad Child Adolesc Psychiatry. 1997;36(6):835-843.

7. McDougle CJ, Stigler KA, Erickson CA, Posey DJ. Atypical antipsychotics in children and adolescents with autistic and other pervasive developmental disorders. J Clin Psychiatry. 2008;69 Suppl 4:15-20.

8. Potenza MN, Holmes JP, Kanes SJ, McDougle CJ. Olanzapine treatment of children, adolescents, and adults with pervasive developmental disorders: an open-label pilot study. J Clin Psychopharmacol. 1999;19(1): $37-44$.

9. Malone RP, Cater J, Sheikh RM, Choudhury MS, Delaney MA. Olanzapine versus haloperidol in children with autistic disorder: an open pilot study. J Am Acad Child Adolesc Psychiatry. 2001;40(8) 887-894. 
10. Hollander E, Wasserman S, Swanson EN, et al. A double-blind placebo-controlled pilot study of olanzapine in childhood/adolescent pervasive developmental disorder. J Child Adolesc Psychopharmacol. 2006;16(5):541-548.

11. Fido A, Al-Saad S. Olanzapine in the treatment of behavioral problems associated with autism: an open-label trial in Kuwait. Med Princ Pract. 2008;17(5):415-418.

12. Martin A, Koenig K, Scahill L, Bregman J. Open-label quetiapine in the treatment of children and adolescents with autistic disorder. J Child Adolesc Psyschopharmacol. 1999;9(2):99-107.

13. Blair J, Scahill L, State M, Martin A. Electrocardiographic changes in children and adolescents treated with ziprasidone: a prospective study. J Am Acad Child Adolesc Psychiatry. 2005;44(1):73-79.

14. Correll CU, Lops JD, Figen V, Malhotra AK, Kane JM, Manu P. QT interval duration and dispersion in children and adolescents treated with ziprasidone. J Clin Psychiatry. 2011;72(6):854-860.

15. Malone RP, Delaney MA, Hyman SB, Cater JR. Ziprasidone in adolescents with autism: an open-label pilot study. $J$ Child Adolesc Psychopharmacol. 2007;17(6):779-790.

16. De Hert M, Dobbelaere M, Sheridan EM, Cohen D, Correll CU. Metabolic and endocrine adverse effects of second-generation antipsychotics in children and adolescents: A systematic review of randomized, placebo controlled trials and guidelines for clinical practice. Eur Psychiatry. 2011;26(3):144-158.

17. Caccia S. Safety and pharmacokinetics of atypical antipsychotics in children and adolescents. Paediatr Drugs. 2013;15(3):217-233.

18. McCracken JT, McGough J, Shah B, et al; Research Units on Pediatric Psychopharmacology Autism Network. Risperidone in children with autism and serious behavioral problems. $N$ Engl J Med. 2002;347(5):314-321.

19. McDougle CJ, Scahill L, Aman MG, et al. Risperidone for the core symptom domains of autism: results from the study by the autism network of the research units on pediatric pharmacology. Am J Psychiatry. 2005;162(6):1142-1148.

20. Shea S, Turgay A, Carroll A, et al. Risperidone in the treatment of disruptive behavioral symptoms in children with autistic and other pervasive developmental disorders. Pediatrics. 2004;114(5):e634-e641.

21. Jesner OS, Aref-Adib M, Coren E. Risperidone for autism spectrum disorder [review]. Cochrane Database Syst Rev. 2007;(1):CD005040.

22. Sharma A, Shaw SR. Efficacy of risperidone in managing maladaptive behaviors in children with autistic spectrum disorder: a meta-analysis. J Pediatr Health Care. 2012;26(4):291-299.

23. Lemmon ME, Gregas M, Jeste SS. Risperidone use in autism spectrum disorders: a retrospective review of a clinic-referred patient population. J Child Neurol. 2011;26(4):428-432.

24. Kent JM, Kushner S, Ning X, et al. Risperidone dosing in children and adolescents with autistic disorder: a double-blind, placebo-controlled study. J Autism Dev Disord. 2013;43(8):1773-1783.

25. Maayan L, Correll CU. Weight gain and metabolic risks associated with antipsychotic medications in children and adolescents. J Child Adolesc Psychopharmacol. 2011;21(6):517-535.

26. Rezaei V, Mohammadi MR, Ghanizadeh A, et al. Double-blind, placebo-controlled trial of risperidone plus topiramate in children with autistic disorder. Prog Neuropsychopharmacol Biol Psychiatry. 2010;34(7):1269-1272.

27. Akhondzadeh S, Fallah J, Mohammadi MR, et al. Double-blind placebo-controlled trial of pentoxifylline added to risperidone: effects on aberrant behavior in children with autism. Prog Neuropsychopharmacol Biol Psychiatry. 2010;34(1):32-36.

28. Ghaleiha A, Asadabadi M, Mohammadi MR, et al. Memantine as adjunctive treatment to risperidone in children with autistic disorder: a randomized, double-blind, placebo-controlled trial. Int $J$ Neuropsychopharmacol. 2013;16(4):783-789.

29. Asadabadi M, Mohammadi MR, Ghanizadeh A, et al. Celecoxib as adjunctive treatment to risperidone in children with autistic disorder: a randomized, double-blind, placebo-controlled trial. Psychopharmacology (Berl). 2013;225(1):51-59.
30. Curran MP. Aripiprazole: in the treatment of irritability associated with autistic disorder in pediatric patients. Paediatr Drugs. 2011;13(3): 197-204.

31. Blankenship K, Erickson CA, Stigler KA, Posey DJ, McDougle CJ. Aripiprazole for irritability associated with autistic disorder in children and adolescents aged 6-17 years. Ped Health. 2010;4(4): 375-381.

32. Owen R, Sikich L, Marcus RN, et al. Aripiprazole in the treatment of irritability in children and adolescents with autistic disorder. Pediatrics. 2009;124(6):1533-1540.

33. Marcus RN, Owen R, Kamen L, et al. A placebo-controlled, fixeddose study of aripiprazole in children and adolescents with irritability associated with autistic disorder. J Am Acad Child Adolesc Psychiatry. 2009;48(11):1110-1119.

34. Ching H, Pringsheim T. Aripiprazole for autism spectrum disorders (ASD) [review]. Cochrane Database Syst Rev. 2012;5:CD009043.

35. Marcus RN, Owen R, Manos G, et al. Aripiprazole in the treatment of irritability in pediatric patients (aged 6-17 years) with autistic disorder: results from a 52-week, open-label study. J Child Adolesc Psychopharmacol. 2011;21(3):229-236.

36. Stigler KA, Diener JT, Kohn AE, et al. Aripiprazole in pervasive developmental disorder not otherwise specified and Asperger's disorder: a 14-week, prospective, open-label study. J Child Adolesc Psychopharmacol. 2009;19(3):265-274.

37. Masi G, Cosenza A, Millepiedi S, Muratori F, Pari C, Salvadori F. Aripiprazole monotherapy in children and young adolescents with pervasive developmental disorders: a retrospective study. CNS Drugs. 2009;23(6):511-521.

38. Lambrey S, Falissard B, Martin-Barrero M, et al. Effectiveness of clozapine for the treatment of aggression in an adolescent with autistic disorder. J Child Adolesc Psychopharmacol. 2010;20(1):79-80.

39. Stigler KA, Mullett JE, Erickson CA, Posey DJ, McDougle CJ. Paliperidone for irritability in adolescents and young adults with autistic disorder. Psychopharmacology (Berl). 2012;223(2):237-245.

40. Stigler KA, Erickson CA, Mullett JE, Posey DJ, McDougle CJ. Paliperidone for irritability in autistic disorder. $J$ Child Adolesc Psychopharmacol. 2010;20(1):75-78.

41. Kowalski JL, Wink LK, Blankenship K, et al. Paliperidone palmitate in a child with autistic disorder. J Child Adolesc Psychopharmacol. 2011;21(5):491-493.

42. Hollander E, Phillips A, Chaplin W, et al. A placebo-controlled crossover trial of liquid fluoxetine on repetitive behaviors in childhood and adolescent autism. Neuropsychopharmacology. 2005;30(3):582-589.

43. DeLong GR, Ritch CR, Burch S. Fluoxetine response in children with autistic spectrum disorders: correlation with familial major affective disorder and intellectual achievement. Dev Med Child Neurol. 2002;44(10): 652-659.

44. Hollander E, Soorya L, Chaplin W, et al. A double-blind placebocontrolled trial of fluoxetine for repetitive behaviors and global severity in adult autism spectrum disorders. Am J Psychiatry. 2012;169(3): 292-299.

45. Sugie Y, Sugie H, Fukuda T, et al. Clinical efficacy of fluvoxamine and functional polymorphism in a serotonin transporter gene on childhood autism. J Autism Dev Disord. 2005;35(3):377-385.

46. Namerow L, Thomas P, Bostic JQ, Prince J, Monuteaux MC. Use of citalopram in pervasive developmental disorders. J Dev Behav Pediatr. 2003;24(2):104-108

47. Owley T, Walton L, Salt J, et al. An open-label trial of escitalopram in pervasive developmental disorders. J Am Acad Child Adolesc Psychiatry. 2005;44(4):343-348.

48. Carrasco M, Volkmar FR, Bloch MH. Pharmacologic treatment of repetitive behaviors in autism spectrum disorders: evidence of publication bias. Pediatrics. 2012;129(5):e1301-e1310

49. Williams K, Wheeler DM, Silove N, Hazell P. Selective serotonin reuptake inhibitors (SSRIs) for autism spectrum disorders (ASD) [review]. Cochrane Database Syst Rev. 2010;(8):CD004677. 
50. Gordon CT, State RC, Nelson JE, Hamburger SD, Rapoport JL. A double-blind comparison of clomipramine, desipramine, and placebo in the treatment of autistic disorder. Arch Gen Psychiatry. 1993;50(6):441-447.

51. Remington G, Sloman L, Konstantareas M, Parker K, Gow R. Clomipramine versus haloperidol in the treatment of autistic disorder: a double-blind, placebo-controlled crossover study. J Clin Psychopharmacol. 2001;21(4):440-444.

52. Hurwitz R, Blackmore R, Hazell P, Williams K, Woolfenden S. Tricyclic antidepressants for autism spectrum disorders (ASD) in children and adolescents [review]. Cochrane Database Syst Rev. 2012;3:CD008372.

53. West $\mathrm{L}$, Brunssen SH, Waldrop J. Review of the evidence for treatment of children with selective serotonin reuptake inhibitors. J Spec Pediatr Nurse. 2009;14(3):183-191.

54. Hollander E, Chaplin W, Soorya L, et al. Divalproex sodium vs placebo for the treatment of irritability in children and adolescents with autism spectrum disorders. Neuropsychopharmacology. 2010;35(4):990-998.

55. Hellings JA, Weckbaugh M, Nickel EJ, et al. A double-blind, placebocontrolled study of valproate for aggression in the youth with pervasive developmental disorders. $J$ Child Adolesc Psychopharmacol. 2005;15(4):682-692.

56. Hollander E, Soorya L, Wasserman S, Esposito K, Chaplin W, Anagnostou E. Divalproex sodium vs placebo in the treatment of repetitive behaviours in autism spectrum disorder. Int J Neuropsychopharmacol. 2006;9(2):209-213.

57. Rugino TA, Samsock TC. Levetiracetam in autistic children: an openlabel study. J Dev Behav Pediatr. 2002;23(4):225-230.

58. Wasserman S, Iyengar R, Chaplin WF, et al. Levetiracetam versus placebo in childhood and adolescent autism: a double-blind placebocontrolled study. Int Clin Psychopharmacol. 2006;21(6):363-367.

59. Siegel M, Beaulieu AA. Psychotropic medications in children with autism spectrum disorders: a systematic review and synthesis for evidence-based practice. J Autism Dev Disord. 2012;42(8):1592-1605.

60. Williamson ED, Martin A. Psychotropic medications in autism: practical considerations for parents. J Autism Dev Disord. 2012;42(6): 1249-1255.

61. Miller NL, Findling RL. Is methylphenidate a safe and effective treatment for ADHD-like symptoms in children with pervasive developmental disorders? Expert Opin Pharmacother. 2007;8(7):1025-1028.

62. Ghuman JK, Aman MG, Lecavalier L, et al. Randomized, placebocontrolled, crossover study of methylphenidate for attentiondeficit/hyperactivity disorder symptoms in preschoolers with developmental disorders. J Child Adolesc Psychopharmacol. 2009; 19(4):329-339.

63. Jahromi LB, Kasari CL, McCracken JT, et al. Positive effects of methylphenidate on social communication and self-regulation in children with pervasive developmental disorders and hyperactivity. J Autism Dev Disord. 2009;39(3):395-404.

64. Davis NO, Kollins SH. Treatment for co-occurring attention deficit/ hyperactivity disorder and autism spectrum disorder. Neurotherapeutics. 2012;9(3):518-530.

65. Quintana H, Birmaher B, Stedge D, et al. Use of methylphenidate in the treatment of children with autistic disorder. J Autism Dev Disord. 1995;25(3):283-294.

66. Handen BL, Johnson CR, Lubetsky M. Efficacy of methylphenidate among children with autism and symptoms of attentiondeficit hyperactivity disorder. J Autism Dev Disord. 2000;30(3): $245-255$.

67. Research Units on Pediatric Psychopharmacology Autism Network. Randomized, controlled, crossover trial of methylphenidate in pervasive developmental disorders with hyperactivity. Arch Gen Psychiatry. 2005;62(11):1266-1274

68. Buitelaar JK, Danckaerts M, Gillberg C, et al; Stomoxetine International Study Group. A prospective, multicenter, open-label assessment of atomoxetine in non-North American children and adolescents with ADHD. Eur Child Adolesc Psychiatry. 2004;13(4):249-257.
69. Ghanizadeh A. Atomoxetine for treating ADHD symptoms in autism: a systematic review. J Atten Disord. 2013;17(8):635-640.

70. Charnsil C. Efficacy of atomoxetine in children with severe autistic disorders and symptoms of ADHD: an open-label study. JAtten Disord. 2011;15(8):684-689.

71. Harfterkamp M, van de Loo-Neus G, Minderaa RB, et al. A randomized double-blind study of atomoxetine versus placebo for attentiondeficit/hyperactivity disorder symptoms in children with autism spectrum disorder. J Am Acad Child Adolesc Psychiatry. 2012;51(7): 733-741.

72. Harfterkamp M, Buitelaar JK, Minderaa RB, et al. Long-term treatment with atomoxetine for attention-deficit/hyperactivity disorder symptoms in children and adolescents with autism spectrum disorder: an open-label extension study. J Child Adolesc Psychopharmacol. 2013;23(3):194-199.

73. Troost PW, Steenhuis MP, Tuynman-Qua HG, et al. Atomoxetine for attention-deficit/hyperactivity disorder symptoms in children with pervasive developmental disorders: a pilot study. $J$ Child Adolesc Psychopharmacol. 2006;16(5):611-619.

74. Arnold LE, Aman MG, Cook AM, et al. Atomoxetine for hyperactivity in autism spectrum disorders: placebo-controlled crossover pilot trial. J Am Acad Child Adolesc Psychiatry. 2006;45(10):1196-1205.

75. Niederhofer H, Damodharan SK, Joji R, Corfield A. Atomoxetine treating patients with Autistic disorder. Autism. 2006;10(6): 647-649.

76. Posey DJ, Wiegand RE, Wilkerson J, Maynard M, Stigler KA, McDougle CJ. Open-label atomoxetine for attention-deficit/hyperactivity disorder symptoms associated with high-functioning pervasive developmental disorders. J Child Adolesc Psychopharmacol. 2006; 16(5):599-610.

77. Zeiner P, Gjevik E, Weidle B. Response to atomoxetine in boys with high-functioning autism spectrum disorders and attention deficit/ hyperactivity disorder. Acta Paediatr. 2011;100(9):1258-1261.

78. Posey DJ, Puntney JI, Sasher TM, Kem DL, McDougle CJ. Guanfacine treatment of hyperactivity and inattention in pervasive developmental disorders: a retrospective analysis of 80 cases. J Child Adolesc Psychopharmacol. 2004;14(2):233-241.

79. Scahill L, Aman MG, McDougle CJ, et al. A prospective open trial of guanfacine in children with pervasive developmental disorders. JChild Adolesc Psychopharmacol. 2006;16(5):589-598.

80. Handen BL, Sahl R, Hardan AY. Guanfacine in children with autism and/or intellectual disabilities. J Dev Behav Pediatr. 2008;29(4): 303-308.

81. Daviss WB, Patel NC, Robb AS, et al. Clonidine for attention-deficit/ hyperactivity disorder: II. ECG changes and adverse events analysis. J Am Acad Child Adolesc Psychiatry. 2008;47(2):189-198.

82. Jaselskis CA, Cook EH Jr, Fletcher KE, Leventhal BL. Clonidine treatment of hyperactive and impulsive children with autistic disorder. J Clin Psychopharmacol. 1992;12(5):322-327.

83. Fankhauser MP, Karumanchi VC, German ML, Yates A, Karumanchi SD. A double-blind, placebo-controlled study of the efficacy of transdermal clonidine in autism. J Clin Psychiatry. 1992;53(3):77-82.

84. Posey DJ, Erickson CA, McDougle CJ. Developing drugs for core social and communication impairment in autism. ChildAdolesc Psychiatr Clin NAm. 2008;17(4):787-801, viii-ix.

85. Andersen IM, Kaczmarska J, McGrew SG, Malow BA. Melatonin for insomnia in children with autism spectrum disorders. $J$ Child Neurol. 2008;23(5):482-485.

86. Galli-Carminati G, Deriaz N, Bertschy G. Melatonin in treatment of chronic sleep disorders in adults with autism: a retrospective study. Swiss Med Wkly. 2009;139(19-20):292-296.

87. Malow B, Adkins KW, McGrew SG, et al. Melatonin for sleep in children with autism: a controlled trial examining dose, tolerability, and outcomes. J Autism Dev Disord. 2012;42(8):1729-1737.

88. Wirojanan J, Jacquemont S, Diaz R, et al. The efficacy of melatonin for sleep problems in children with autism, fragile X syndrome, or autism and fragile X syndrome. J Clin Sleep Med. 2009;5(2):145-150. 
89. Wright B, Sims D, Smart S, et al. Melatonin versus placebo in children with autism spectrum conditions and severe sleep problems not amenable to behaviour management strategies: a randomised controlled crossover trial. J Autism Dev Disord. 2011;41(2):175-184.

90. Cortesi F, Giannotti F, Sebastiani T, Panunzi S, Valente D. Controlledrelease melatonin, singly and combined with cognitive behavioural therapy, for persistent insomnia in children with autism spectrum disorders: a randomized placebo-controlled trial. J Sleep Res. 2012;21(6):700-709.

91. Freeman MP, Hibbeln JR, Wisner KL, et al. Omega-3 fatty acids: evidence basis for treatment and future research in psychiatry. J Clin Psychiatry. 2006;67(12):1954-1967.

92. Bent S, Bertoglio K, Hendren RL. Omega-3 fatty acids for autistic spectrum disorder: a systemic review. J Autism Dev Disord. 2009; 39(8):1145-1154.

93. James S, Montgomery P, Williams K. Omega-3 fatty acids supplementation for autism spectrum disorders (ASD) [review]. Cochrane Database Syst Rev. 2011;(11):CD007992.

94. Flashner BM, Russo ME, Boileau JE, Leong DW, Gallicano GI. Epigenetic factors and autism spectrum disorders. Neuromolecular Med. 2013;15(2):339-350.

95. Chao HT, Chen H, Samaco RC, et al. Dysfunction in GABA signaling mediates autism-like stereotypies and Rett syndrome phenotypes. Nature. 2010;468(7321):263-269.

96. D'Hulst C, Heulens I, Brouwer JR, et al. Expression of the GABAergic system in animal models for fragile $\mathrm{X}$ syndrome and fragile $\mathrm{X}$ associated tremor/ataxia syndrome (FXTAS). Brain Res. 2009;1253:176-183

97. Ehninger D, Silva AJ. Rapamycin for treating Tuberous sclerosis and Autism spectrum disorders. Trends Mol Med. 2011;17(2):78-87.

98. Hussman JP, Chung RH, Griswold AJ, et al. A noise-reduction GWAS analysis implicates altered regulation of neurite outgrowth and guidance in autism. Mol Autism. 2011;2(1):1.

99. Jacob S, Brune CW, Badner JA, et al. Family-based association testing of glutamate transporter genes in autism. Psychiatr Genet. 2011;21(4): 212-213.

100. Fatemi SH, Reutiman TJ, Folsom TD, Thuras PD. GABA(A) receptor downregulation in brains of subjects with autism. JAutism Dev Disord. 2009;39(2):223-230.

101. Shimmura C, Suda S, Tsuchiya KJ, et al. Alteration of plasma glutamate and glutamine levels in children with high-functioning autism. PLoS One. 2011;6(10):e25340

102. Abu Shmais GA, Al-Ayadhi LY, Al-Dbass AM, El-Ansary AK. Mechanism of nitrogen metabolism-related parameters and enzyme activities in the pathophysiology of autism. J Neurodev Disord. 2012;4(1):4.

103. Harada M, Taki MM, Nose A, et al. Non-invasive evaluation of the GABAergic/glutamatergic system in autistic patients observed by MEGA-editing proton MR spectroscopy using a clinical 3 tesla instrument. J Autism Dev Disord. 2011;41(4):447-454.

104. Essa MM, Braidy N, Vijayan KR, Subash S, Guillemin GJ. Excitotoxicity in the pathogenesis of autism. Neurotox Res. 2013;23(4):393-400.

105. Silverman JL, Tolu SS, Barkan CL, Crawley JN. Repetitive self-grooming behavior in the BTBR mouse model of autism is blocked by the mGluR5 antagonist MPEP. Neuropsychopharmacology. 2010;35(4):976-989.

106. Burket JA, Herndon AL, Winebarger EE, Jacome LF, Deutsch SI. Complex effects of mGluR5 antagonism on sociability and stereotypic behaviors in mice: possible implications for the pharmacotherapy of autism spectrum disorders. Brain Res Bull. 2011;86(3-4):152-158.

107. Modi ME, Young LJ. D-cycloserine facilitates socially reinforced learning in an animal model relevant to autism spectrum disorders. Biol Psychiatry. 2011;70(3):298-304.
108. Lemonnier E, Degrez C, Phelep M, et al. A randomised controlled trial of bumetanide in the treatment of autism in children. Transl Psychiatry. 2012;2:e202.

109. Erickson CA, Posey DJ, StiglerKA, Mullett J, KatschkeAR, McDougle CJ. A retrospective study of memantine in children and adolescents with pervasive developmental disorders. Psychopharmacology (Berl). 2007;191(1):141-147.

110. Niederhofer H. Glutamate antagonists seem to be slightly effective in psychopharmacologic treatment of autism. J Clin Psychopharmacol. 2007;27(3):317-318.

111. Owley T, Salt J, Guter S, et al. A prospective, open-label trial of memantine in the treatment of cognitive, behavioral, and memory dysfunction in pervasive developmental disorders. J Child Adolesc Psychopharmacol. 2006;16(5):517-524.

112. Chez MG, Burton Q, Dowling T, Chang M, Khanna P, Kramer C. Memantine as adjunctive therapy in children diagnosed with autistic spectrum disorders: an observation of initial clinical response and maintenance tolerability. J Child Neurol. 2007;22(5):574-579.

113. Erickson CA, Early M, Stigler KA, Wink LK, Mullett JE, McDougle CJ. An open-label naturalistic pilot study of acamprosate in youth with autistic disorder. J Child Adolesc Psychopharmacol. 2011;21(6): 565-569.

114. Green JJ, Hollander E. Autism and oxytocin: new developments in translational approaches to therapeutics. Neurotherapeutics. 2010;7(3):250-257.

115. Hollander E, Novotny S, Hanratty M, et al. Oxytocin infusion reduces repetitive behaviors in adults with autistic and Asperger's disorders. Neuropsychopharmacology. 2003;28(1):193-198.

116. Hollander E, Bartz J, Chaplin W, et al. Oxytocin increases retention of social cognition in autism. Biol Psychiatry. 2007;61(4):498-503.

117. Andari E, Duhamel JR, Zalla T, Herbrecht E, Leboyer M, Sirigu A. Promoting social behavior with oxytocin in high-functioning autism spectrum disorders. Proc Natl Acad Sci U S A. 2010;107(9): 4389-4394.

118. Tachibana M, Kagitani-Shimono K, Mohri I, et al. Long-term administration of intranasal oxytocin is a safe and promising therapy for early adolescent boys with autism spectrum disorders. J Child Adolesc Psychopharmacol. 2013;23(2):123-127.

119. Guastella AJ, Einfeld SL, Gray KM, et al. Intranasal oxytocin improves emotion recognition for youth with autism spectrum disorders. Biol Psychiatry. 2010;67(7):692-694.

120. Anagnostou E, Soorya L, Chaplin W, et al. Intranasal oxytocin versus placebo in the treatment of adults with autism spectrum disorders: a randomized controlled trial. Mol Autism. 2012;3(1):16.

121. Domes G, Heinrichs M, Kumbier E, Grossmann A, Hauenstein K, Herpertz SC. Effects of intranasal oxytocin on the neural basis of face processing in autism spectrum disorder. Bio Psychiatry. 2013;74(3): 164-171.

122. Guerini FR, Bolognesi E, Chiappedi M, et al. HLA polymorphisms in Italian children with autism spectrum disorder: Results of a family based linkage study. J Neuroimmunol. 2011;230(1-2):135-142.

123. Guerini FR, Bolognesi E, Chiappedi M, et al. Activating KIR molecules and their cognate ligands prevail in children with a diagnosis of ASD and in their mothers. Brain Behav Immun. 2013.

124. Ghezzo A, Guerini FR, Bolognesi E, et al. Neuropsychological gender differences in healthy individuals and in pediatric neurodevelopmental disorders. A role for SNAP-25. Med Hypotheses. 2009;73(6): 978-980.

125. Guerini FR, Bolognesi E, Chiappedi M, et al. SNAP-25 single nucleotide polymorphisms are associated with hyperactivity in autism spectrum disorders. Pharmacol Research. 2011;64(3):283-288. 
Neuropsychiatric Disease and Treatment

Dovepress

\section{Publish your work in this journal}

Neuropsychiatric Disease and Treatment is an international, peerreviewed journal of clinical therapeutics and pharmacology focusing on concise rapid reporting of clinical or pre-clinical studies on a range of neuropsychiatric and neurological disorders. This journa is indexed on PubMed Central, the 'PsycINFO' database and CAS.

The manuscript management system is completely online and includes a very quick and fair peer-review system, which is all easy to use. Visit http://www.dovepress.com/testimonials.php to read real quotes from published authors.

\footnotetext{
Submit your manuscript here: http://www.dovepress.com/neuropsychiatric-disease-and-treatment-journal
} 